\title{
Premedication with dexmedetomidine to reduce emergence agitation: a randomized controlled trial
}

\author{
Jong Chan Kim, Jihee Kim, Hayeon Kwak and So Woon Ahn * (D)
}

\begin{abstract}
Background: Nasal bone fracture is the most common type of facial fracture, and the high incidence of severe emergence agitation occurring after closed reduction of the nasal bone fracture can be challenging to manage. The purpose of this trial was to evaluate whether pre-operative administration of dexmedetomidine is effective in reducing the incidence and severity of emergence agitation in adults undergoing closed reduction of nasal bone fractures.

Methods: In this randomized controlled trial, 90 patients who were scheduled to undergo closed reduction of a nasal bone fracture were prospectively included and were randomly assigned to either the control group $(n=45$; $0.9 \%$ saline infusion) or the dexmedetomidine group ( $n=45 ; 1 \mu / \mathrm{kg}$ over $10 \mathrm{~min}$, pre-operatively). The primary endpoint was Aono's four-point scale scores after anesthesia. The recovery time and numeric rating scale score were assessed as secondary endpoints.

Results: Aono's four-point scale scores were lower in the dexmedetomidine group than in the control group (median: 1 [1] vs. 1 [1, 2], 95\% confidence interval of difference: 0.01 to $0.02, P=0.02$ ). The number, severity, and duration of agitation episodes were significantly lower in the dexmedetomidine group than in the control group. Furthermore, the number of patients exhibiting intraoperative movement was lower in the dexmedetomidine group.

Conclusions: Pre-operative administration of dexmedetomidine demonstrated several significant benefits, such as a lower incidence of emergence agitation, reduced agitation severity, and a shorter duration of agitation. Additionally, we observed more stable maintenance of intraoperative anesthesia with less movement during the surgery.
\end{abstract}

Trial registration: Identifier: KCT0000585 (registration date: 12-19- 2012).

Keywords: Dexmedetomidine, Emergence agitation, Nasal bone fracture

\section{Background}

Nasal bone fracture is the most common type of facial fracture [1] and the third most common fracture type of the human skeleton [2]. One treatment method for nasal bone fracture is closed reduction (CR), which can be performed under local or general anesthesia [3]. General anesthesia facilitates patient comfort, improves patient satisfaction, [4] and helps maintain patient immobilization during surgery. However, external splints or nasal packing is also commonly used for stabilization after CR because there is no pinning

\footnotetext{
* Correspondence: iatria@hanmail.net

Department of Anesthesiology and Pain Medicine, CHA Bundang Medical Center, CHA University, 59 Yatap-ro, Bundang-gu, Seongnam-si, Gyeonggi-do 13496, South Korea
}

(c) The Author(s). 2019 Open Access This article is distributed under the terms of the Creative Commons Attribution 4.0 International License (http://creativecommons.org/licenses/by/4.0/), which permits unrestricted use, distribution, and reproduction in any medium, provided you give appropriate credit to the original author(s) and the source, provide a link to the Creative Commons license, and indicate if changes were made. The Creative Commons Public Domain Dedication waiver (http://creativecommons.org/publicdomain/zero/1.0/) applies to the data made available in this article, unless otherwise stated.

or fixation of the nasal bones. These can be uncomfortable for patients, causing difficulty with breathing; this contributes to the incidence of emergence agitation (EA), which can cause re-dislocation of a corrected fracture.

EA can necessitate physical or chemical restraint of the patients [5]. EA commonly occurs after otolaryngological procedures, which poses additional challenges [6]. The incidence of EA following nasal surgery has been reported to be $4.7-27.3 \%[7,8]$.

Dexmedetomidine, a specific $\alpha^{2}$-adrenergic receptor agonist, has been shown to be effective in preventing EA in children [9-12]. According to a recent meta-analysis, intraoperative administration of dexmedetomidine decreases postoperative pain and the incidence of EA in adults [13]. 
The objective of the present study was to evaluate whether pre-operative intravenous infusion of dexmedetomidine is effective in reducing the incidence and severity of EA in adults undergoing $\mathrm{CR}$ of a nasal bone fracture.

\section{Methods}

After obtaining approval from the Institutional Review Board (IRB number: 12-071, protocol number: Ver 1, Date of approval: 9/26/2012), written informed consent was obtained from all enrolled participants. This manuscript adheres to the applicable CONSORT guidelines. The participants in this study were 20 to 60 years of age, American Society of Anesthesiologists class 1 or 2, and were scheduled to undergo CR of a nasal bone fracture under general anesthesia between November 2012 and September 2013. One-hundred eight patients were prospectively included. Patients were excluded from the study if they had a known history or clinical evidence of chronic obstructive pulmonary disease or respiratory insufficiency based on pre-operative medications or a pulmonary function test. Patients were also excluded if they had a history of renal or hepatic dysfunction, sleep apnea syndrome, recent symptoms of an upper respiratory infection, or if they were taking beta-blockers. Ninety patients were randomly assigned to either the control group or dexmedetomidine group one day before surgery. Randomized group allocation was performed using a computerized randomization table created by one staff member who was not involved in the patient's anesthesia or recovery care. The flowchart of the patient enrollment process is shown in (Fig. 1). Staff members who provided clinical care for participants and collected the clinical data for this study were blinded to the patients' group allocation.

Standardized anesthetic management was provided to all patients. Upon arrival at the pre-anesthetic room, standard monitoring was applied to each patient by an attending nurse who was not involved in this study, which included electrocardiography, pulse oximetry, and a non-invasive blood pressure cuff. Patients were re-educated that they might feel discomfort postoperatively due to the nasal packing. The control group received $0.5 \mathrm{ml} \cdot \mathrm{kg}^{-1} 0.9 \%$

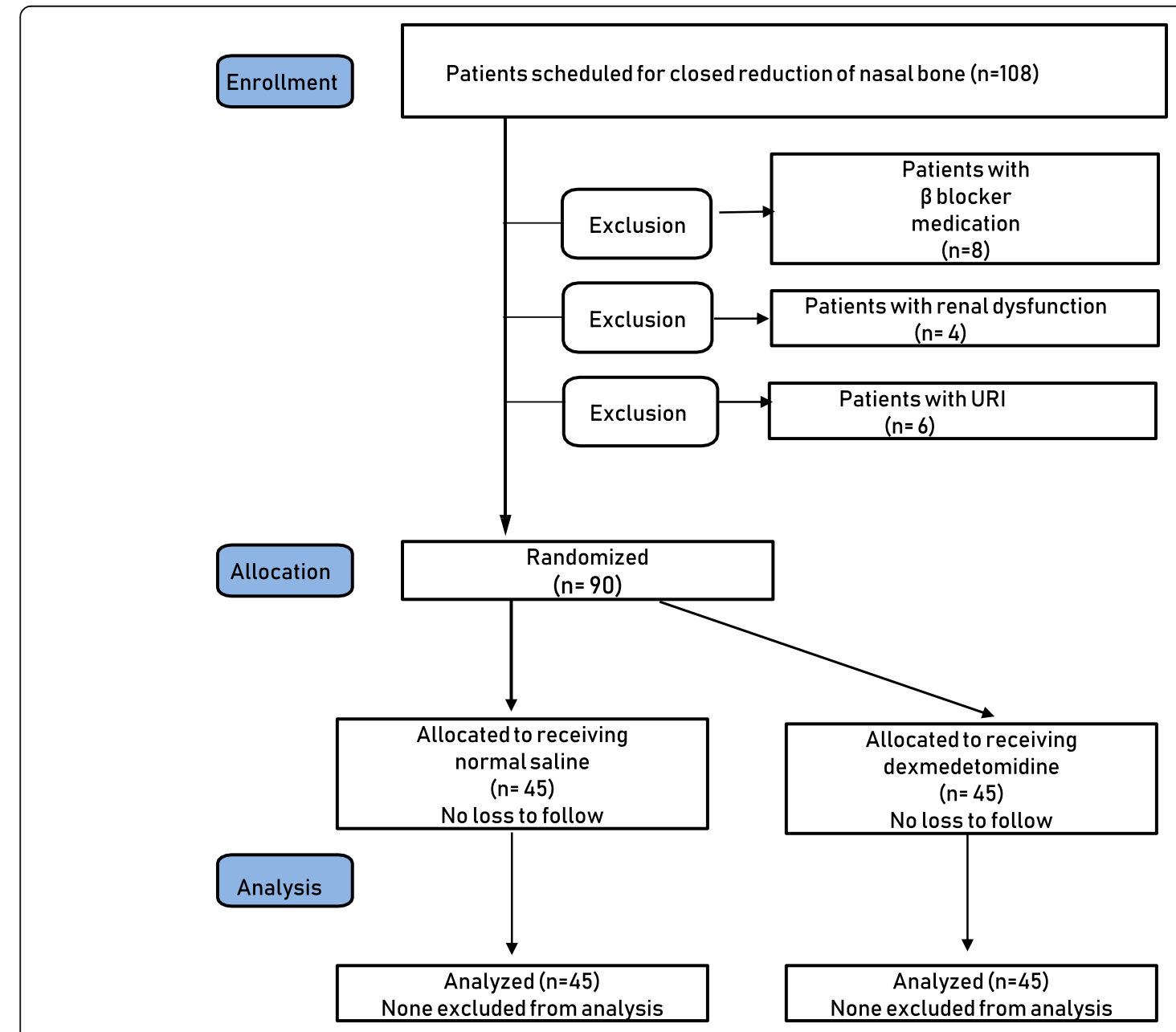

Fig. 1 Flow chart of patient participation 
saline intravenously over $10 \mathrm{~min}$ before anesthetic induction. The dexmedetomidine group received dexmedetomidine $1 \mu \mathrm{g} \cdot \mathrm{kg}^{-1}$ (Precedex, Hospira Worldwide, Lake Forest, IL, USA) in an equal volume of saline, intravenously, over $10 \mathrm{~min}$ before anesthetic induction. All the study medications were administered by a single researcher, who was not involved in any other part of this study. No other sedative premedications were given to the study participants.

On arrival at the operating theatre, we checked the patient's sedation scale (Richmond Agitation-Sedation Scale, RASS) scores before anesthetic drug administration. Anesthesia was induced with fentanyl $1 \mu \mathrm{g} \cdot \mathrm{kg}^{-1}$ and propofol $2 \mathrm{mg} \cdot \mathrm{kg}^{-1}$. The patient's lungs were ventilated using a face mask with $100 \%$ oxygen, and succinylcholine $1 \mathrm{mg} \cdot \mathrm{kg}^{-1}$ was administrated intravenously. After muscle relaxation was achieved, the patient's trachea was intubated. During the operation, anesthesia was maintained with fentanyl and sevoflurane which was titrated to maintain a bispectral index (BIS) value between 40 and 60. Mechanical ventilation parameters during anesthesia were standardized to maintain normocarbia. If the patient's blood pressure was $20 \%$ lower than the baseline value, intravenous ephedrine was administered. At the conclusion of the operation, once the nasal splint was attached, all anesthetic agents were discontinued, and 100\% oxygen was administered. After confirmation that the patient had fully recovered from muscle relaxation and after the patient opened his or her eyes to verbal stimulation, the trachea was extubated, and the patient was transferred to the post-anesthesia care unit (PACU).

Because patients responded to verbal stimulation, EA was assessed using Aono's four-point scale (Appendix), and pain was evaluated using the numeric rating scale (NRS, 0-10) at 2-min intervals until the patient was discharged from the PACU; the peak NRS and Aono's scores were then recorded. Anesthesia time, operative time, the time from the end of the operation to extubation, and the duration of EA were recorded by the patient's attending anesthesiologist. In the PACU, if the patient requested additional analgesics or if the patient's NRS score was 3 or more, meperidine $25 \mathrm{mg}$ was administered intravenously and repeated as required. All doses of rescue analgesics and the duration of the PACU stay were also recorded by an attending PACU staff who was not involved in the anesthesia administration or the current study.

The primary endpoint of this study was the incidence of emergence agitation (Aono's scores $\geq 2$ ) after general anesthesia. The recovery time and NRS score were assessed as secondary endpoints. All study variables were evaluated and recorded by an investigator who was blinded to the patients' group allocation.

SPSS software version 22 (SPSS Inc.; Chicago, IL, USA) was used for the statistical analyses and all values are expressed as the number of patients (proportion), mean (standard deviation $[\mathrm{SD}]$ ), or the median (interquartile range $[\mathrm{IQR}]$ or confidence interval $[\mathrm{CI}]$ ) as appropriate. The sample size was calculated based on the primary endpoint of agiatation incidence. On the basis of an institutional preliminary study, we determined that 45 patients would be required in each group to detect a $25 \%$ difference in the incidence of Aono's scores $\geq 2$ between the groups, with a power of $80 \%$ and an alpha level of 0.05 . Allowing for a $20 \%$ drop-out rate during the study period, we enrolled 54 patients in each group. Two-way repeated-measures analysis of variance was used for data on blood pressure, heart rate, oxygen saturation, and BIS. The Student $t$-test was used for the comparisons of intragroup values of intraoperative and postoperative mean blood pressure and heart rate. Nonparametric data such as NRS and Aono's four-point scale were compared between groups with the Mann-Whitney $U$ test. The Fischer exact test was used to compare patient sex; the percentage of patients in each group with intraoperative movement; the number of patients rescued with meperidine or intravenous labetalol or ephedrine; and those with episodes of severe EA. A Pvalue of 0.05 or less was considered statistically significant.

\section{Results}

All study participants underwent successful CR of the nasal bone fracture without any complications associated with anesthesia or surgery; the data of 90 of the 108 eligible participants between October 2012 and September 2013 were used in the analysis (Fig. 1). Patient characteristics and operation-related data, including the operation duration and the use of nasal packing after surgery, were not statistically different between the groups (Table 1).

Blood pressure $(P=0.182)$, heart rate $(P=0.272)$ and oxygen saturation $(P=0.478)$ were similar between the two groups. The preoperative RASS scores were also comparable between the two groups $(P=0.073)$. Aono's scores after anesthesia were lower in the dexmedetomidine group than those in the control group (median [IQR]: 1 [1] vs. $1[1,2]$, 95\% CI of difference: 0.07 to 0.69 , mean difference: $0.4, P=$ 0.015). Agitation duration (mean $[\mathrm{SD}] ; 0.3$ [1] min vs. 2.5 [6]

Table 1 Patient characteristics and operation-related data for each group

\begin{tabular}{lll}
\hline & $\begin{array}{l}\text { Control } \\
(n=45)\end{array}$ & $\begin{array}{l}\text { Dexmedetomidine } \\
(n=45)\end{array}$ \\
\hline Age, years & $39(15)$ & $36(12)$ \\
Male & $31(69)$ & $34(76)$ \\
Weight, $\mathrm{kg}$ & $67(11)$ & $69(13)$ \\
BMl, $\mathrm{kg} \mathrm{m}{ }^{-2}$ & $23.4(2.8)$ & $23.3(3.4)$ \\
Operation time, min & $6(5)$ & $6(4)$ \\
Postoperative bilateral nasal packing & $40(89)$ & $38(84)$
\end{tabular}

Values are number of patients (proportion) or mean (SD); BMI Body mass index 
min; mean difference: $2.1 \mathrm{~min}, 95 \% \mathrm{CI}$ of difference: 0.37 to $3.88, P=0.019$ ) and the number of agitated patients(Aono's score $\geq 2$ ) were lower in the dexmedetomidine group than those in the control group (Table 2). There were also fewer patients who showed severe agitation (Aono's score $\geq 3$ ) in the dexmedetomidine group (Table 2). Additionally, fewer patients in the dexmedetomidine group than in the control group showed movement during the operation (number [proportion] 6 [13] vs. 0 [0], $P=0.01$ ) (Table 3).

There was no significant difference in the NRS pain scores between the two groups $(P=0.37)$. The duration of the PACU stay was longer in the dexmedetomidine group (mean [SD]: 32 min [11] vs. 41 min [11]: mean difference: $9.18,95 \%$ CI of difference: 13.9 to 4.4 , $P<0.001$ ); however, the anesthesia time was shorter in the dexmedetomidine group (mean [SD]; 24 [9] min vs. 20 [6] min: mean difference: $3.6 \mathrm{~min}, 95 \% \mathrm{CI}$ of difference: 0.4 to $6.7, P=0.03$ ) (Table 1 , Table 3 ).

\section{Discussion}

In this randomized, controlled trial of adult patients undergoing $\mathrm{CR}$ of a nasal bone fracture, pre-operative administration of intravenous dexmedetomidine demonstrated several benefits such as a lower incidence of EA, reduced agitation severity, and a shorter duration of agitation. In addition to these beneficial effects on EA, we observed more stable maintenance of intraoperative anesthesia with less movement during surgery in patients who were premedicated with dexmedetomidine. Furthermore, there was no statistical difference between the groups in terms of the incidence of complications, such as pre-operative sedation and hypo- or hypertension; however, the PACU stay duration was longer in the dexmedetomidine group.

EA after anesthesia is common during the immediate postoperative period; however, its etiology in adults is unclear, and serious sequelae of EA have rarely been studied in adult patients [14, 15]. Many factors predispose a patient to EA, which is frequently initiated by uncomfortable stimuli [16]. Nasal surgery is known to be associated with a relatively high incidence of EA $[6,13]$. After a CR of a nasal fracture, external splints and nasal packing are commonly used to stabilize and protect the

Table 2 Agitation scale and numeric rating scale scores

\begin{tabular}{llll}
\hline & $\begin{array}{l}\text { Control } \\
(n=45)\end{array}$ & $\begin{array}{l}\text { Dexmedetomidine } \\
(n=45)\end{array}$ & $P$ value \\
\hline NRS & $4(2-5)$ & $3(2-6)$ & 0.374 \\
Aono's scale & $1(1-2)$ & $1(1-1)$ & $0.015^{\mathrm{a}}$ \\
$\begin{array}{l}\text { Agitation (Aono's scale } \\
\text { scores } \geq 2)\end{array}$ & $18(40.0)$ & $8(17.8)$ & $0.020^{\mathrm{a}}$ \\
Agitation duration (min) & $2.5(6)$ & $0.3(1)$ & $0.019^{\mathrm{a}}$ \\
Aono's scale scores $\geq 3$ & $9(20.0)$ & $2(4.4)$ & $0.024^{\mathrm{a}}$ \\
\hline
\end{tabular}

Values are number (proportion), mean (SD) or median (interquartile range); NRS (numeric rating scale); ${ }^{a}, P$ value $<0.05$
Table 3 Intra operation- and post operation-related data

\begin{tabular}{|c|c|c|c|c|}
\hline & $\begin{array}{l}\text { Control } \\
(n=45)\end{array}$ & $\begin{array}{l}\text { Dexmedetomidine } \\
(n=45)\end{array}$ & $\begin{array}{l}\text { Mean } \\
\text { difference } \\
(95 \% \mathrm{Cl})\end{array}$ & $P$ value \\
\hline $\begin{array}{l}\text { Pre-operative } \\
\text { RASS scores } \\
\leq-2\end{array}$ & $0(0 \%)$ & $2(4 \%)$ & NA & 0.49 \\
\hline $\begin{array}{l}\text { Intra-operative } \\
\text { movement }\end{array}$ & $6(13)$ & $0(0)$ & NA & $0.01^{a}$ \\
\hline $\begin{array}{l}\text { End of operation } \\
\text { to extubation, min }\end{array}$ & $5(3)$ & $4(2)$ & 1.1 (-0.4 to 2.2$)$ & 0.07 \\
\hline $\begin{array}{l}\text { Anesthesia } \\
\text { time, min }\end{array}$ & $24(9)$ & $20(6)$ & 3.6 (0.4 to 6.7$)$ & $0.03^{\mathrm{a}}$ \\
\hline $\begin{array}{l}\text { PACU stay } \\
\text { time, min }\end{array}$ & $32(11)$ & $41(11)$ & $\begin{array}{l}-9.0(-13.9 \\
\text { to }-4.4)\end{array}$ & $<0.001^{\mathrm{a}}$ \\
\hline
\end{tabular}

Values are number of patients (proportion) or mean (SD); RASS:

Richmond Agitation-Sedation Scale; PACU: Post anesthetic care unit; ${ }^{\text {a }}, P$ value $<0.05$

reduction in lieu of screw insertion or fixation. The presence of external splints and nasal packing can be uncomfortable and make it difficult for patients to breathe, possibly contributing to the development of EA. Severe EA can result in nasal bleeding, re-dislocation of the reduced fracture, and even the need for reoperation. Additionally, in patients who develop respiratory depression after anesthesia, respiratory support with a face mask or airway can be difficult.

Dexmedetomidine induces sedation and analgesia without respiratory depression [17]. Several studies have advocated the beneficial effects of intraoperative administration of dexmedetomidine for reducing the incidence of perioperative morbidities after nasal surgery, such as intraoperative bleeding, postoperative pain, and EA $[13,18,19]$. Considering the short length of CR surgery, an intraoperative infusion of dexmedetomidine as an anesthetic adjuvant may prolong the anesthesia and recovery time [20]. Previous studies have shown that a single -dose of dexmedetomidine, not as a premedication, is also effective in reducing EA and facilitating smooth extubation after pediatric adenotonsillectomy [10]. However, there were no reports about single-dose premedication of dexmedetomidine in adult patients. Thus, we aimed to evaluate the efficacy of pre-operative dexmedetomidine administration in preventing or reducing the severity of EA in adults undergoing $\mathrm{CR}$ of a nasal bone fracture.

In our study, fewer patients developed EA, and the severity of agitation was also significantly lower in the dexmedetomidine group as compared to previous studies. Two patients in the dexmedetomidine group developed pre-operative sedation (RASS score $\leq-3$, no verbal response); however, no patients showed desaturation $\left(\mathrm{SpO}_{2}<95 \%\right)$, and the incidence of sedation was not statistically different between the two groups $(P=0.49)$. Even though the duration of the PACU stay was significantly longer in the dexmedetomidine group than in the control group, the anesthesia time was significantly shorter in the dexmedetomidine group. This may 
be due to a higher incidence of agitation in the control group. Transport to the PACU after extubation is sometimes delayed in patients who experience EA because of patient safety concerns. In this study, the time from the end of surgery to extubation was not significantly different between the two groups, and the duration of the PACU stay was clinically acceptable in both groups (32 min vs. $41 \mathrm{~min}$ ).

Dexmedetomidine can cause hemodynamic changes including hypotension, hypertension, and bradycardia [21]. We analyzed the patients' mean arterial pressure at three-time points (baseline, pre-operative, and postoperative in the PACU) and there were no significant differences between the groups $(P=0.75)$. Furthermore, there was no patient who showed hypotension that required ephedrine in both groups. One patient developed bradycardia (heart rate $<45$ beats per minute) and was treated with ephedrine; however, the incidence of bradycardia was not statistically different between the groups $(P=0.93)$. The use of pre-operative dexmedetomidine showed no analgesic advantage as the NRS pain scores in the PACU were not different between the two groups. Even though a standardized anesthetic technique and administration of a muscle relaxant was used in both groups, significantly fewer patients in the dexmedetomidine group showed movement during the operation; therefore, pre-operative dexmedetomidine may be useful as an adjuvant anesthetic to help maintain stable intra-operative anesthesia.

\section{Limitations}

First, we did not assess the effect of different doses of dexmedetomidine. According to the results of a previous study, a single dose of dexmedetomidine $\left(0.5 \mu \mathrm{g} \cdot \mathrm{kg}^{-1}\right)$ was effective in reducing EA in children [10]. In this study, we used a larger dose of $1 \mu \mathrm{g} \cdot \mathrm{kg}^{-1}$, and there was no significant difference in the incidence of hypo- or hypertension, bradycardia, or other side effects related to dexmedetomidine between the two groups. Second, we did not evaluate the effect of dexmedetomidine on the inhalational anesthetic dose. The dose of sevoflurane was titrated to maintain a specific BIS range, but we did not compare the inhalational anesthetic consumption and we could not directly assess the anesthetic-sparing-effect of the premedicated dexmedetomidine. It would be worthwhile to perform a future study using a different dose of dexmedetomidine and controlled inhalational anesthetic drug.

\section{Conclusions}

This study concluded that the administration of pre-operative dexmedetomidine lowers the incidence of EA, reduces agitation severity, and shortens the duration of agitation without complications after CR of a nasal bone fracture. The administration of pre-operative dexmedetomidine can also minimize patient movement during the operation.

\section{Appendix}

Table 4 Aono's four-point scale

Calm

Not calm but could be easily consoled

Moderately agitated or restless and not easily calmed

Combative, excited, or disoriented, thrashing around

\section{Abbreviations}

BIS: Bispectral index; Cl: Confidence interval; CR: Closed reduction; EA: Emergence agitation; IQR: Interquartile range; NRS: Numeric rating scale; PACU: Post-anesthesia care unit; RASS: Richmond Agitation-Sedation Scale score; SD: Standard deviation

\section{Aknowledgements \\ Not applicable}

\section{Authors' contributions}

KJC: Enrolling study participants and interpretation of data. KJ: Performing statistical analysis and acquisition of data. $\mathrm{KH}$ : Enrolling study participants and acquisition of data. ASW: Designing the study, performing all statistical analysis, and drafting the manuscript, and revising it critically for important intellectual content. All authors have read and approved the maniscript.

\section{Funding}

Not applicable

\section{Availability of data and materials}

The datasets generated and analyzed during the current study are not publicly available as permission from participants to publicity share the dataset has not been obtained.

However, these datasets are available from the corresponding author on reasonable request.

\section{Ethics approval and consent to participate}

After obtaining approval from the Myungii Hospital Institutional Review Board (IRB number: 4-2008-0583), the study was performed in Kwandong University Muyngji Hospital. Written informed consent was obtained from all subjects participating in the trial.

\section{Consent for publication}

Not applicable

\section{Competing interests}

The authors declare that they have no competing interest.

Received: 8 April 2019 Accepted: 29 July 2019

Published online: 07 August 2019

\section{References}

1. Rhee SC, Kim YK, Cha JH, Kang SR, Park HS. Septal fracture in simple nasal bone fracture. Plast Reconstr Surg. 2004;113(1):45-52.

2. Murray JA, Maran AG, Mackenzie IJ, Raab G. Open v closed reduction of the fractured nose. Arch Otolaryngol. 1984;110(12):797-802.

3. Mondin V, Rinaldo A, Ferlito A. Management of nasal bone fractures. Am J Otolaryngol. 2005;26(3):181-5.

4. Lee K, Yoo BH, Yon JH, Kim KM, Kim MC, Lee WY, Lee S, Lim YH, Nam SH, Choi YW, et al. General anesthesia versus monitored anesthetic care with dexmedetomidine for closed reduction of nasal bone fracture. Korean J Anesthesiol. 2013:65(3):209-14.

5. Lepouse C, Lautner CA, Liu L, Gomis P, Leon A. Emergence delirium in adults in the post-anaesthesia care unit. Br J Anaesth. 2006;96(6):747-53.

6. Yu D, Chai W, Sun X, Yao L. Emergence agitation in adults: risk factors in 2,000 patients. Can J Anaesth. 2010;57(9):843-8.

7. Kim HJ, Kim DK, Kim HY, Kim JK, Choi SW. Risk factors of emergence agitation in adults undergoing general anesthesia for nasal surgery. Clin Exp Otorhinolaryngol. 2015;8(1):46-51. 
8. Kim YS, Chae YK, Choi YS, Min JH, Ahn SW, Yoon JW, Lee SE, Lee YK. A comparative study of emergence agitation between sevoflurane and propofol anesthesia in adults after closed reduction of nasal bone fracture. Korean J Anesthesiol. 2012;63(1):48-53.

9. Shukry M, Clyde MC, Kalarickal PL, Ramadhyani U. Does dexmedetomidine prevent emergence delirium in children after sevoflurane-based general anesthesia? Paediatr Anaesth. 2005;15(12):1098-104.

10. Guler G, Akin A, Tosun Z, Ors S, Esmaoglu A, Boyaci A. Single-dose dexmedetomidine reduces agitation and provides smooth extubation after pediatric adenotonsillectomy. Paediatr Anaesth. 2005;15(9):762-6.

11. Mountain BW, Smithson L, Cramolini M, Wyatt TH, Newman M. Dexmedetomidine as a pediatric anesthetic premedication to reduce anxiety and to deter emergence delirium. AANA J. 2011;79(3):219-24.

12. Ibacache ME, Munoz HR, Brandes V, Morales AL. Single-dose dexmedetomidine reduces agitation after sevoflurane anesthesia in children. Anesth Analg. 2004;98(1):60-3 table of contents.

13. Lee HS, Yoon HY, Jin HJ, Hwang SH. Can Dexmedetomidine influence recovery profiles from general anesthesia in nasal surgery? Otolaryngol Head Neck Surg. 2018;158(1):43-53.

14. Lipov EG. Emergence delirium in the PACU. Crit Care Nurs Clin North Am. 1991;3(1):145-9.

15. O'Brien D. Acute postoperative delirium: definitions, incidence, recognition, and interventions. J Perianesth Nurs. 2002;17(6):384-92.

16. Fricchione GL, Nejad SH, Esses JA, Cummings TJ Jr, Querques J, Cassem NH, Murray GB. Postoperative delirium. Am J Psychiatry. 2008;165(7):803-12.

17. Gerlach AT, Dasta JF. Dexmedetomidine: an updated review. Ann Pharmacother. 2007;41 (2):245-52

18. Kim SY, Kim JM, Lee JH, Song BM, Koo BN. Efficacy of intraoperative dexmedetomidine infusion on emergence agitation and quality of recovery after nasal surgery. Br J Anaesth. 2013;111(2):222-8.

19. Kim YH, Yoon SZ, Lim HJ, Yoon SM. Prophylactic use of midazolam or propofol at the end of surgery may reduce the incidence of emergence agitation after sevoflurane anaesthesia. Anaesth Intensive Care. 2011;39(5): 904-8.

20. Garg A, Kamal M, Mohammed S, Singariya G, Chouhan DS, Biyani G. Efficacy of dexmedetomidine for prevention of emergence agitation in patients posted for nasal surgery under desflurane anaesthesia: a prospective double-blinded randomised controlled trial. Indian J Anaesth. 2018;62(7): 524-30

21. Bhana N, Goa KL, McClellan KJ. Dexmedetomidine. Drugs. 2000;59(2):263-8 discussion 269-270.

\section{Publisher's Note}

Springer Nature remains neutral with regard to jurisdictional claims in published maps and institutional affiliations.

Ready to submit your research? Choose BMC and benefit from:

- fast, convenient online submission

- thorough peer review by experienced researchers in your field

- rapid publication on acceptance

- support for research data, including large and complex data types

- gold Open Access which fosters wider collaboration and increased citations

- maximum visibility for your research: over $100 \mathrm{M}$ website views per year

At $\mathrm{BMC}$, research is always in progress.

Learn more biomedcentral.com/submissions 